\title{
CAPSULORHEXIS PHYMOSIS FOLLOWING UNCOMPLICATED PHACOEMULSIFICATION SURGERY
}

\author{
H. J. ZAMBARAKJI, S. RAUZ, A. REYNOLDS, N. JOSHI, P. R. SIMCOCK and P. E. KINNEAR \\ London
}

\begin{abstract}
SUMMARY
Purpose: The aim of the study was to assess and compare the degree of capsulorhexis phymosis following uncomplicated phacoemulsification cataract surgery in polymethylmethacrylate (PMMA) and silicone lens implants.

Method: Sixty-four patients were evaluated 1 day, 6 weeks and 6 months following phacoemulsification cataract extraction. The anterior capsular diameters were measured with the illuminated beam of the slit lamp at $45^{\circ}$ and $135^{\circ}$ and the surface area of the opening calculated. We have measured and compared the change in the capsulorhexis size for both lens types and assessed its statistical significance with a paired Student's $t$-test.

Results: A statistically significant contraction of the capsulorhexis was noted in all patients within the first 6 weeks $(p<0.001)$. Capsular contraction continued between 6 weeks and 6 months post-operatively but to a lesser extent $(p<0.05)$. The difference in the degree of phymosis between the first period (1 day to 6 weeks) and the second (6 weeks to 6 months) was statistically highly significant for all patients $(p<0.001)$. The capsular areas for the silicone lens implants were significantly smaller than for the PMMA implants at 6 weeks and 6 months. None of our patients had a clinically significant capsular contracture requiring Nd:YAG laser capsulotomy.

Conclusion: Anterior capsular contraction is commonly observed following capsulorhexis in phacoemulsification surgery. This study demonstrates that the maximum rate of contraction occurs in the first 6 weeks following surgery and is more pronounced with silicone lens implants.
\end{abstract}

From: Department of Ophthalmology, Charing Cross Hospital, Fulham Palace Road, London W6 8RF, UK.

Correspondence to: Mr H. J. Zambarakji, Department of Ophthalmology, Queen's Medical Centre, Nottingham NG7 2UH, UK.
In recent years phacoemulsification has become widely used amongst cataract surgeons in the United Kingdom. One of the fundamental steps in the procedure involves fashioning a well-positioned and adequately sized continuous curvilinear capsulorhexis (CCC). The advantages of the $\mathrm{CCC}^{1}$ have made this the preferred method of anterior capsulotomy amongst $80 \%$ of the members of the American Society of Cataract and Refractive Surgery. ${ }^{2}$ The capsulorhexis allows safe long-term inthe-bag intraocular lens centration ${ }^{3}$ and the absence of jagged edges confers elasticity preventing peripheral radial tears to the equator and beyond, preserving an intact capsular sac. Complications of the CCC are rare. ${ }^{4}$ The capsule contraction syndrome (CCS) refers to the exaggerated reduction of the anterior capsulotomy and capsular bag diameter originally described after extracapsular cataract surgery. ${ }^{5}$

We present a series of 64 patients who underwent uncomplicated phacoemulsification of their cataract with in-the-bag intraocular lens implantation (polymethylmethacrylate (PMMA) or silicone) and evaluate and compare the extent of capsular phymosis.

\section{PATIENTS AND METHODS}

One eye each of the 64 patients underwent routine sutureless phacoemulsification surgery under peribulbar local anaesthesia performed by two surgeons (P.R.S., N.J.). All patients had surgery performed through a corneal tunnel; cortical lens matter was completely removed with an automated irrigation aspiration device and the intraocular lenses were implanted on a bed of Healonoid. Two designs of intraocular lenses were implanted:

Group 1: polymethylmethacrylate (PMMA), one piece, $\mathrm{CZ}$ Alcon, optic size $5 \times 6 \mathrm{~mm}, 5^{\circ}$ slant. 


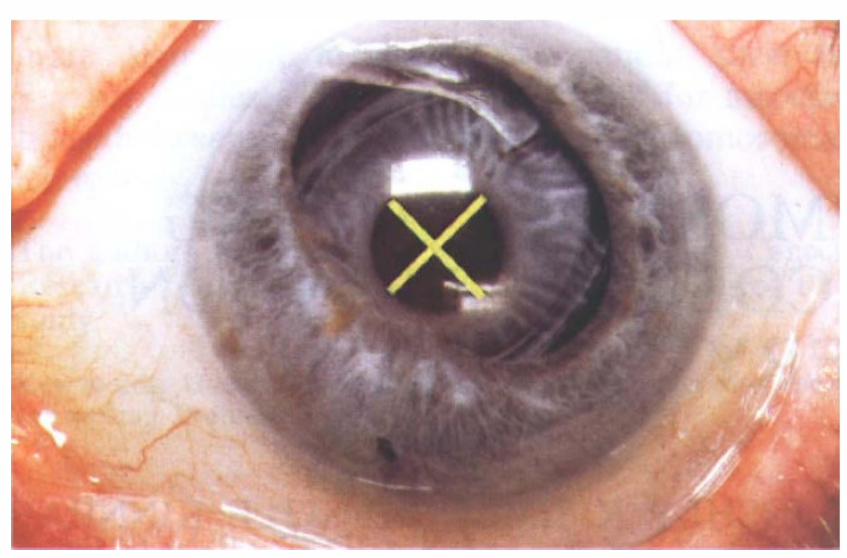

Fig. 1. The mean of the two diameters measured at $45^{\circ}$ and $135^{\circ}$ was used to calculate the capsular area opening.

Group 2: Silicone optic/polypropylene haptics, three piece, Allergan, optic size $6 \times 6 \mathrm{~mm}, 10^{\circ}$ slant.

All patients had betamethasone $2 \mathrm{mg}$ and tobramycin $20 \mathrm{mg}$ subconjunctivally at the end of their surgery. The operated eyes were examined on day 1 , week 6 and 6 months post-operatively. The capsulorhexis was visualised by dilating the pupil and the diameters were measured along the $45^{\circ}$ and $135^{\circ}$ meridians with the observation and illumination axes of the slit lamp in the co-axial position (Fig. 1). The area within the capsulorhexis opening was calculated $\left(\pi r^{2}\right)$ using the mean of the two diameters measured. We calculated the percentage reduction in area and the corresponding statistical significance using the paired Student's $t$-test during: (1) time period 1, day 1 to week 6 ; (2) time period 2, week 6 to 6 months. The percentage change in capsular opening was calculated after eliminating the time factor by scaling our measurements to 6 weekly period intervals. All patients were commenced on g. dexamethasone $0.1 \%$ and g. chloramphenicol $0.5 \%$ four times a day during the first week post-operatively and this was gradually reduced over the next 4 weeks. Patients excluded from the series were those with a previous history of diabetes, glaucoma, pseudoexfoliation, ocular inflammation or other forms of ocular co-morbidity.

\section{RESULTS}

Twenty-nine patients had PMMA and 35 had silicone intraocular lens implants. The average age of the patients in group 1 was $75 \pm 1.7$ years (range 57-89 years) and $76 \pm 1.5$ years (range 61-91 years) in group 2. There were 26 men and 38 women.

There was a significant reduction in area within the capsular opening in all patients (Fig. 2). In group 1 the mean percentage reduction during period 1 was $16.14 \%(p<0.001)$ and that in period 2 was $2.4 \%$ $(p<0.05)$. In group 2 the reduction was $19.9 \%$ $(p<0.001)$ and $7.5 \%(p=0.001)$, respectively. The difference in the percentage change between the two time periods was statistically significant for both groups $(p<0.001)$. These results are summarised in Table I. The capsular areas for silicone lens implants at 6 weeks and 6 months post-operatively were significantly smaller than for the PMMA lens implants $(p=0.0001$ and $p=0.0002$ respectively). The mean capsular diameters are given in Table II.

\section{DISCUSSION}

Phymosis of the anterior capsule opening is a recognised complication of capsulorhexis ${ }^{6}$ and is particularly common in patients with pseudoexfoliation, ${ }^{5}$ although Hansen et al. ${ }^{4}$ did not observe a significant contraction in more than 250 cases of cataract extraction in patients with pseudoexfoliation.

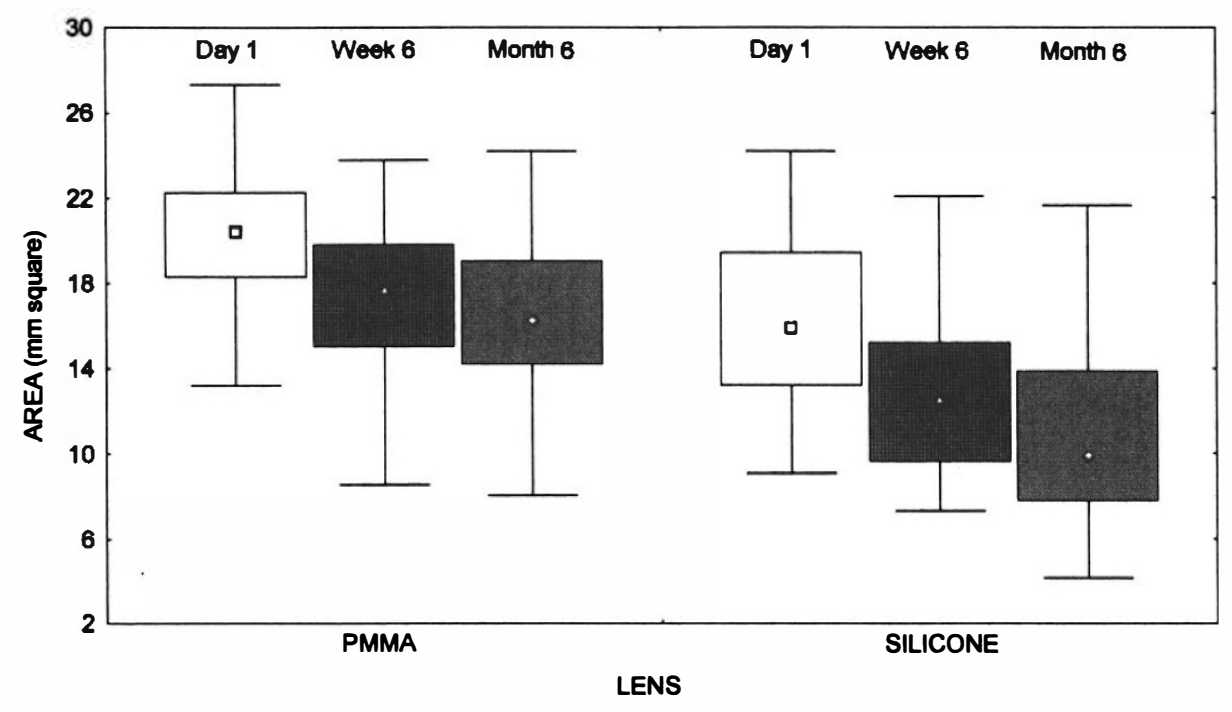

Fig. 2. Capsular area distribution: the boxes represent the middle $50 \%$ of areas measured (interquartile range $H$ ) with the median value marked. The whiskers represent measurements that lie within $1.5 \mathrm{H}$ of the lower and upper quartiles. 
Table I. Percentage change in capsular areas

\begin{tabular}{|c|c|c|}
\hline & \multicolumn{2}{|c|}{ Change in capsular area (\%) } \\
\hline & Period 1 & Period 2 \\
\hline $\begin{array}{l}\text { Group } 1 \text { (PMMA) } \\
\text { Group } 2 \text { (silicone) }\end{array}$ & $\begin{array}{ll}-16.14 \% & (p<0.001) \\
-19.9 \% & (p<0.001)\end{array}$ & $\begin{array}{l}-2.4 \%(p<0.05) \\
-7.5 \%(p=0.001)\end{array}$ \\
\hline
\end{tabular}

This study shows a significant reduction in the capsular opening following uncomplicated phacoemulsification in eyes with no ocular co-morbidity; this was greatest during the first 6 weeks postoperatively. Furthermore this reduction is more pronounced if foldable silicone lenses are implanted. Despite this, none of our patients developed a clinically significant change necessitating Nd:YAG laser anterior capsulotomy. Such intervention has been reported in patients with pseudoexfoliation, ${ }^{5}$ uveitis,${ }^{5,7}$ pars planitis, ${ }^{4,5}$ myotonic dystrophy, ${ }^{4}$ high myopia, ${ }^{4}$ retinitis pigmentosa ${ }^{8}$ and multifocal chorioretinitis. ${ }^{9}$ A marked capsular shrinkage may reduce vision by obscuring the visual axis or by causing decentration of the intraocular lens by asymmetric bag contracture. ${ }^{6}$ The CCS may also compound the visibility of the peripheral retina, creating a problem during peripheral retinal photocoagulation and vitreoretinal surgery. If capsule contracture is noted, Davison $^{5}$ has suggested Nd:YAG laser anterior capsulotomies as early as 2-3 weeks post-operatively.

Decentration and dislocation of the intraocular lens have been described following capsular contracture. Decentration has been demonstrated in the rabbit eye model to be associated with asymmetrical capsular shrinkage following an irregular-shaped capsulorhexis, ${ }^{10}$ and was greatest in the presence of a threepiece lens with polypropylene haptics and least with a compressible disc lens. More marked contracture has been reported to lead to complete intraocular lens dislocation into the vitreous and retinal detachment. ${ }^{5}$ None of our patients, however, developed a visually disabling decentration and there was no incidence of a dislocated lens or retinal detachment.

The anterior capsular fibrosis is thought to be induced by cytokines released by lens epithelial cells. ${ }^{11-13}$ Histological examination has revealed several layers of proliferated spindle cells and abundant extracellular matrix consisting of collagen fibres under the monolayer of lens epithelium attached to the anterior capsule. The spindle cells are thought to be derived from the lens epithelium as they exhibit junctional complexes which are a feature of the epithelium. Severe anterior capsular shrinkage

Table II. Capsular diameters (mean \pm 2 standard deviations), in millimetres

\begin{tabular}{lccc}
\hline & Day 1 & Week 6 & Month 6 \\
\hline Group 1 (PMMA) & $5.10 \pm 1.00$ & $4.64 \pm 1.14$ & $4.53 \pm 1.18$ \\
Group 2 (silicone) & $4.52 \pm 1.24$ & $4.00 \pm 1.12$ & $3.69 \pm 1.42$ \\
\hline
\end{tabular}

is thought to be due to the low resistance of the lens supporting system, i.e. the zonular fibres and anterior vitreous, combined with the centrally directed unopposed pull generated by the fibrosing anterior capsular edge. ${ }^{14}$ It is therefore possible to avoid capsulorhexis-related complications by anterior capsule vacuuming, which would eliminate the anterior subcapsular and equatorial lens epithelial cells. ${ }^{15}$

In summary, our data demonstrate that anterior capsular phymosis following a CCC in uncomplicated phacoemulsification surgery is common and its rate is greatest during the first 6 post-operative weeks. However, due to the relatively small numbers examined, no conclusions can be drawn on the incidence of clinically significant capsular phymosis. This phenomenon is greatest following the use of silicone foldable lens implants and we therefore recommend the use of rigid one-piece PMMA lens material with a broad, relatively firm haptic structure in predisposed eyes. We believe that surgical technique is equally important and support the view that the complete removal of cortical lens matter is necessary.

We would like to thank Dr J. Emami at the Chelsea and Westminster Hospital, London, for his assistance with the statistical analysis, as well $\mathrm{Mr} \mathrm{D}$. Andrews and $\mathrm{Mr} \mathrm{D}$. O'Driscoll at Charing Cross Hospital, London, for their help in carrying out the study.

Key words: Continuous curvilinear capsulorhexis, Capsule contraction syndrome, Capsulotomy, Phacoemulsification.

\section{REFERENCES}

1. Gimbel HV, Neumann T. Development, advantages and methods of the CCC technique. J Cataract Refract Surg 1990;16:31-7.

2. Leaming DV. Practice styles and preferences of ASCRS Members: 1992 Survey. J Cataract Refract Surg 1993;19:600-6.

3. Colvard DM, Dunn SA. Intraocular lens centration with continuous tear capsulotomy. J Cataract Refract Surg 1990;16:312-31.

4. Hansen SO, Crandall AS, Olson RJ. Progressive constriction of the anterior capsular opening following intact capsulorhexis. J Cataract Refract Surg 1993; 19:77-82.

5. Davison JA. Capsule contraction syndrome. J Cataract Refract Surg 1993;19:582-9.

6. Masket S. Postoperative complications of capsulorhexis. J Cataract Refract Surg 1993;19:721-4.

7. Young DA, Orlin SE. Capsulorhexis contracture in phacoemulsification surgery. Ophthalmic Surg 1994; 25:477-8.

8. Nishi O, Nishi K. Intraocular lens encapsulation by shrinkage of the capsulorhexis opening. J Cataract Refract Surg 1993;19:544-5.

9. Behrendt S, Wetzel W. Complete occlusion of the capsulorhexis incision by anterior capsule shrinkage. Ophthalmologe 1994;91:526-8.

10. Ohmi S, Uenoyama K. Decentration associated with asymmetrical capsular shrinkage and intraocular lens design in a rabbit model. J Cataract Refract Surg 1995;21:293-6. 
11. Nishi O, Nishi K, Imanishi M. Synthesis of interleukin1 and prostaglandin $E_{2}$ by lens epithelial cells of human cataracts. Br J Ophthalmol 1992;76:338-41.

12. Yokoyama T. Interleukin-1 beta in the aqueous humor in aphakic and pseudophakic eyes of rabbits. Acta Soc Ophthalmol Jpn 1992;96:67-73.

13. Malecaze F, Chollet P, Cavrois E, et al. Role of interleukin-6 in the inflammatory response after cataract surgery; an experiment and clinical study. Arch Ophthalmol 1991;109:1681-3.
14. Namiki M, Tagami Y, Morino I, Kano M, Sugiura T. Findings from slit-lamp and histological examination of the anterior capsule of patients with severe anterior capsular shrinkage and opacities after implantation of intraocular lenses. Nippon Ganka Gakkai Zasshi. Acta Soc Ophthalmol Japonicae 1993;97:716-20.

15. Nishi O. Intercapsular cataract surgery with lens epithelial cell removal. II. Effect on prevention of fibrinous reaction. J Cataract Refract Surg 1989;15: 301-3. 